\title{
Pelatihan Menanam Kangkung dengan Sistem Hidroponik WICK di Kelurahan Tampa Garam Distrik Maladum Mes Kota Sorong
}

\author{
Nurul Fajeriana M. \\ Fakultas Pertanian, Universitas Muhammadiyah Sorong, Papua Barat, Indonesia. \\ Email: nurfariana_miu2@yahoo.co.id
}

\begin{abstract}
ABSTRAK
Kelurahan Tampa Garam yang wilayahnya berada di wilayah pesisir Kota Sorong dengan keterbatasan pada jenis tanah, curah hujan yang tinggi, topografi dari landai hinga curam, kepemilikan lahan, menjadi sulit untuk budidaya dalam bentuk pertanian konvensional. Sehingga untuk dapat memenuhi kemandirian pangan dalam hal sayuran maka dilakukan pelatihan budidaya kangkung dengan teknik hidroponik WICK yang lebih mudah dan murah. Kegiatan Pelatihan dilaksanakan pada hari Kamis, 25 April 2019 pukul 14.00 - 17.25 WIT, bertempat di Kantor Kelurahan Tampa Garam. Adapun peserta pelatihan terdiri dari ibu-ibu rumah tangga, anggota PKK Kelurahan Tampa Garam,dan juga bapak-bapak yang tidak ketinggalan turut ambil bagian dalam pelatihan. Total peserta pelatihan yakni 68 orang. Pelatihan dilakukan dengan memulai pemaparan atau pengenalan tentang Pertanian Hidroponik, yang dilajutkan dengan mempraktekkan tahapan budidaya, mulai dari cara melarutkan Pupuk ABmix, cara menyemai benih kangkung, dan cara menanam dengan teknik hidroponik WICK. Setelah mempratekkan, peserta kemudian diberi kesempatan untuk mencontohkan setiap tahapan. Antusiame warga yang luar biasa dalam pelatihan budidaya dengan teknik hidroponik yang merupakan hal yang baru bagi peserta sehingga seringkali tejadi diskusi disela-sela praktek yang dilakukan, dan pemateri masih terus mendampingi bahkan selalu mengulang rangkaian proses hingga peserta benar-benar mahir dan bisa melakukannya sendiri di rumah. Pelatihan dengan hidroponik WICK tidak memerlukan lahan yang luas melainkan pekarangan sempit yang dimiliki warga, sehingga tetap bisa bercocok tanam dan proses perawatan yang gampang dengan produksi yang banyak biasa membantu warga dalam menghemat pengeluaran atau belanja akan sayuran.
\end{abstract}

Kata Kunci: Hidroponik WICK, Kangkung, Sorong.

\begin{abstract}
Tampa Garam Urban Village, which is located in the coastal area of Sorong City with limitations on soil types, high rainfall, topography of steep hamps, land ownership, becomes difficult to cultivate in conventional farming. So as to be able to meet food independence in terms of vegetables, water spinach cultivation training is carried out with the WICK hydroponic technique that is easier and cheaper. Training activities will be held on Thursday, April 25, 2019 from 14.00 - 17.25 WIT, located at the Tampa Garam District Office. The training participants consisted of housewives, members of the PKK of Tampa Garam Village, and also fathers who did not miss taking part in the training. The total training participants were 68 people. The training is carried out by starting with the presentation or introduction of Hydroponic Agriculture, which is continued by practicing the stages of cultivation, starting from how to dissolve ABmix Fertilizer, how to sow kale seeds, and how to plant using WICK hydroponic techniques. After practicing, participants are then given the opportunity to model each stage. The enthusiasm of the extraordinary citizens in the cultivation training with hydroponic techniques is new to the participants so that discussions often occur between practices, and presenters continue to assist even in always repeating the series of processes until the participants are truly proficient and can do it themselves at House. The training with WICK hydroponics does not require a large area of land but a narrow yard owned by the residents, so that they can still grow crops and an easy maintenance process with a lot of production used to help residents save money or spend on vegetables.

Keywords: Hydroponic WICK, Kale, Sorong
\end{abstract}




\section{PENDAHULUAN}

Keterbatasan lahan yang semakin meningkat seperti sekarang ini menyebabkan produktivitas pertanian semakin menurun. Banyaknya lahan produktif yang dialihfungsikan menjadi areal pemukiman dan industri (non-pertanian), sedangkan pemenuhan kebutuhan akan pangan semakin meningkat. Apalagi pada daerah perkotaan yang lahannya sudah semakin menyusut atau sempit. Namun dengan sistem pertanian hidroponik hambatan lahan bisa diatasi dengan produksi yang sama dengan sistem pertanian konvensional. Wijaya dan Nurul (2018) menyatakan bahwa semakin terbatasnya lahan pertanian di Indonesia, mengharuskan memilih alternatif sistem budidaya yang bisa digunakan dan mampu tetap menjaga hasil dari tanaman. Sistem pertanian hidroponik yaitu budidaya menanam dengan memanfaatkan air tanpa menggunakan tanah dengan menekankan pada pemenuhan kebutuhan nutrisi bagi tanaman melalui media air.

Sistem hidroponik yang kelebihannya selain tidak menggunakan tanah sebagai media tanam, juga bisa dilakukan dimana saja dan tidak bergantung pada musim, bahkan di wilayah pesisir dengan iklim panas pun bisa tumbuh dengan baik seperti halnya di Kelurahan Tampa Garam yang wilayahnya berada di wilayah pesisir Kota Sorong.

Kelurahan Tampa Garam adalah salah satu kelurahan yang ada di Distrik Maladum Mes Kota Sorong. Topografi daerahnya mulai dari landai hingga berlereng curam/terjal $(3-35 \%)$. Karena berada disepanjang pesisir kota Sorong maka jenis tanah yang mendominasi adalah Litosol dengan tekstur berpasir. Selain itu daerahnya tinggi curah hujan. Dimana peruntukan untuk pertanian konvensional mengalami banyak kendala, sehingga sangat sesuai apabila masyarakat bisa mebudidayakan sayuran dengan sistem hidroponik.

Dalam pelatihan ini dipilih sayuran Kangkung berdasarkan permintaan dari masyarakat dan juga pelatihan ini menggunakan metode sederhana yakni dengan sistem hidroponik WICK yang tidak membutuhkan banyak biaya karena menggunakan barang-barang bekas, yakni botolbotol plastik air mineral.

\section{METODE PELAKSANAAN KEGIATAN}

\section{Waktu, Tempat dan Peserta}

Kegiatan Pelatihan dilaksanakan pada hari Kamis, 25 April 2019 pukul 14.00 - 17.25 WIT, bertempat di Kantor Kelurahan Tampa Garam. Adapun peserta pelatihan terdiri dari ibu-ibu 
rumah tangga, anggota PKK Kelurahan Tampa Garam,dan juga bapak-bapak yang tidak ketinggalan turut ambil bagian dalam pelatihan. Total peserta pelatihan yakni 68 orang.

\section{Bahan dan Alat Pelatihan}

Adapun bahan dan alat yang digunakan dalam pelatihan hidroponik WICK yakni Laptop, LCD Proyektor, Botol plastic Bekas Air mineral ukuran 1,5 L, Bibit tanaman kangkong, Pupuk AB Mix, Benih Kangkung, Bibit Kangkung yang telah disemai, Aquades/Air Galon, Sumbu, Rockwool, Lakban hitam, Talang, Pengaduk, Baskom atau ember, Gunting, Pisau atau Cutter, Timba, Paku, dan Solder

\section{Tahapan Pelatihan}

Sebelum memulai demontrasi cara menanam dengan sistem hidroponik WICK, terebih dahulu pemateri memaparkan pengenalan tentang sistem hiroponik, maksud dan tujuannnya, keuntungan dari sistem hidroponik, alasan memilih sistem hidroponik WICK.

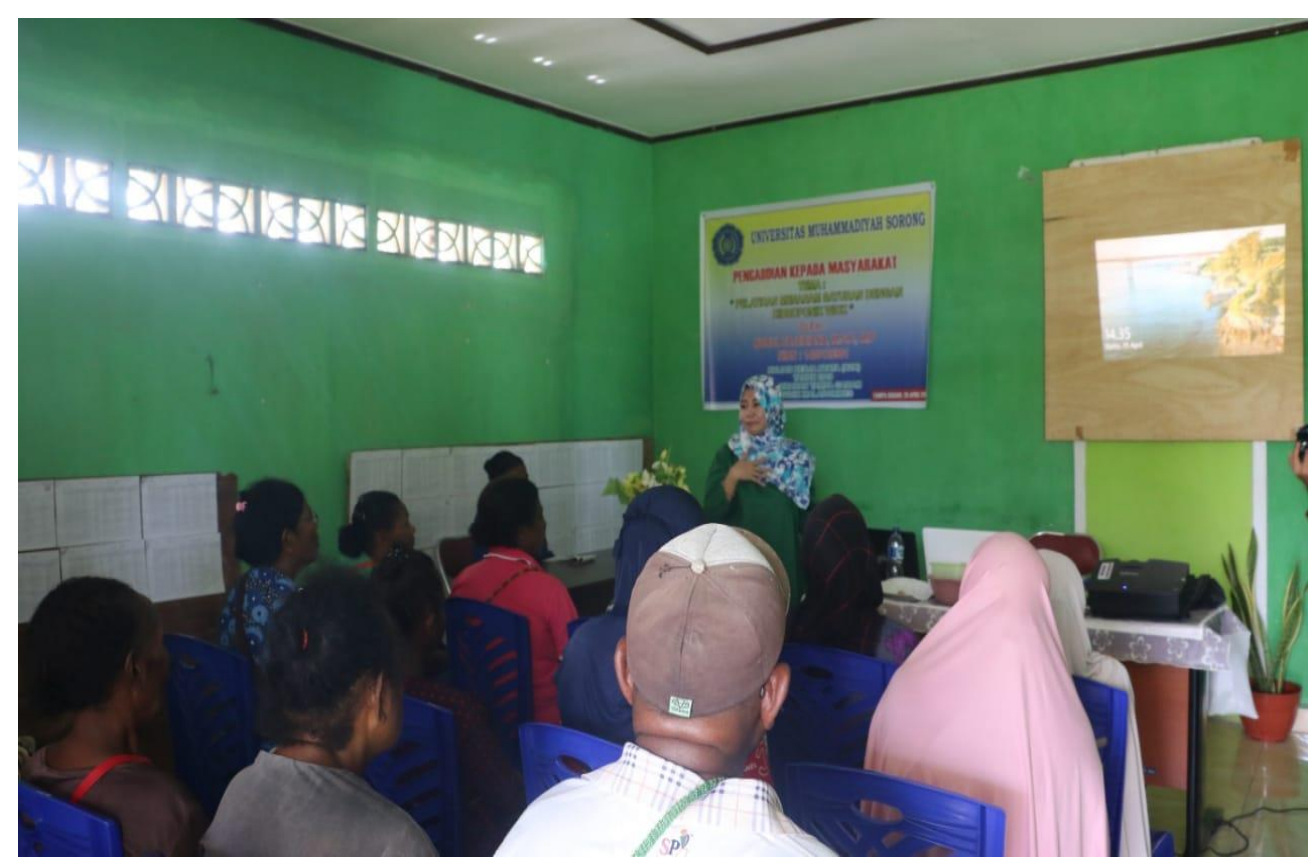

Gambar 1. Pemaparan oleh pemateri kepada peserta mengenai Pertanian Hidroponik.

Setelah proses pemaparan selesai, pemateri memulai sesi diskusi dengan warga masyarakat atau peserta pelatihan yang hadir. Hal ini dilakukan agar para peserta bisa memahami dengan jelas tentang bercocok tanam dengan sistem Hidroponik WICK.

Dari hasil diskusi yang dilakukan ternyata peserta pelatihan sangat antusias. Sebagian dari peserta ada yang sudah pernah melihat proses bertani dengan sistem hidroponik yakni degan bantuan pompa untuk mengerakkan sirkulasi air. 
Setelah proses diskusi, pemateri melanjutkan dengan pengenalan pupuk untuk hidroponik yakni ABmix. Memperlihatkan contoh pupuk dan memberi informasi cara mendapatkan pupuk.

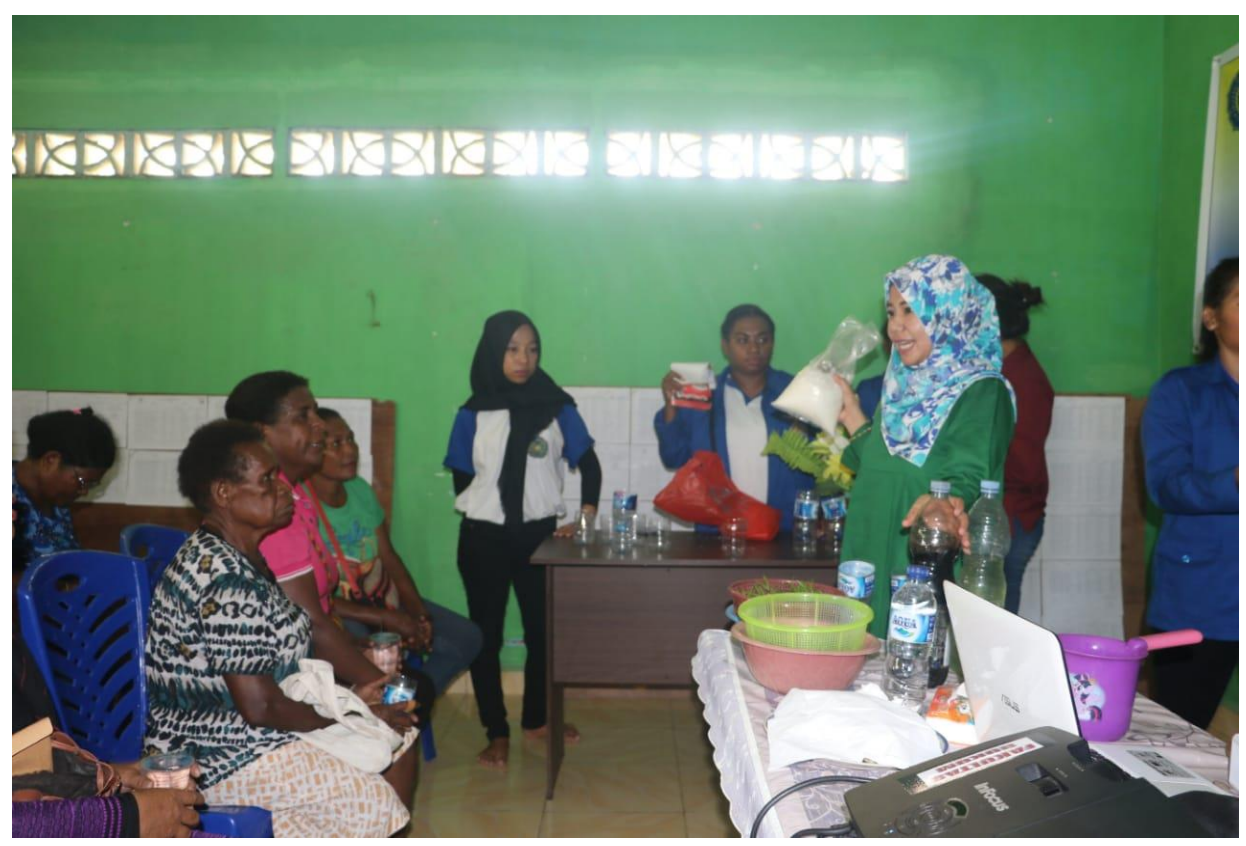

Gambar 2. Pemateri memperlihatkan pupuk ABmix kepada peserta.

Adapun tahapan prosedur kerja yang dicontohkan pemateri kepada peserta pelatihan yakni:

\section{a) Cara Melarutkan Pupuk AB Mix.}

1) Melarutkan masing-masing pupuk ABmix yakni masing-masing pupuk A dan B dimasukkan kedalam baskom/ember lalu diberi air. perbandingannya yakni 1 bungkus pupuk dilarutkan dengan 5 liter Air.

2) Selanjutnya, mengaduk hingga semua butiran pupuk larut dengan air.

3) Pupuk yang telah dilarutkan kemudian disimpan dalam wadah tertutup agar tidak tumpah.

\section{b) Cara Menyemai Benih Kangkung}

1) Rendam benih dalam baskom,

2) Buang benih yang mengapung, karena benih yang mengapung menandakan peluang tumbuhnya kecil atau mutunya tidak bagus, sedangkan yang tenggelam berarti berisi dan peluang tumbuhnya besar.

3) Benih yang tenggelam kemudian disaring,

4) Satu persatu benih kemudian ditanam pada rockwool yang sdh dibasahi terlebih dahulu dengan air dan disimpan dalam talang.

5) Selanjutnya penyemaian dilakukan dengan semalaman ditaruh pada tempat yang gelap, dan besok harinya dikeluarkan untuk mendapatkan cahaya matahari. 


\section{c) Cara menanam dengan Hidroponik WICK}

1) Mengambil botol plastik bekas ai mineral lalu memotong menjadi 2 bagian menggunakan cutter atau pisau dengan tidak membuang tutup botol. Ukuran botol bagian bawah lebih besar daripada ukuran bagian atas.

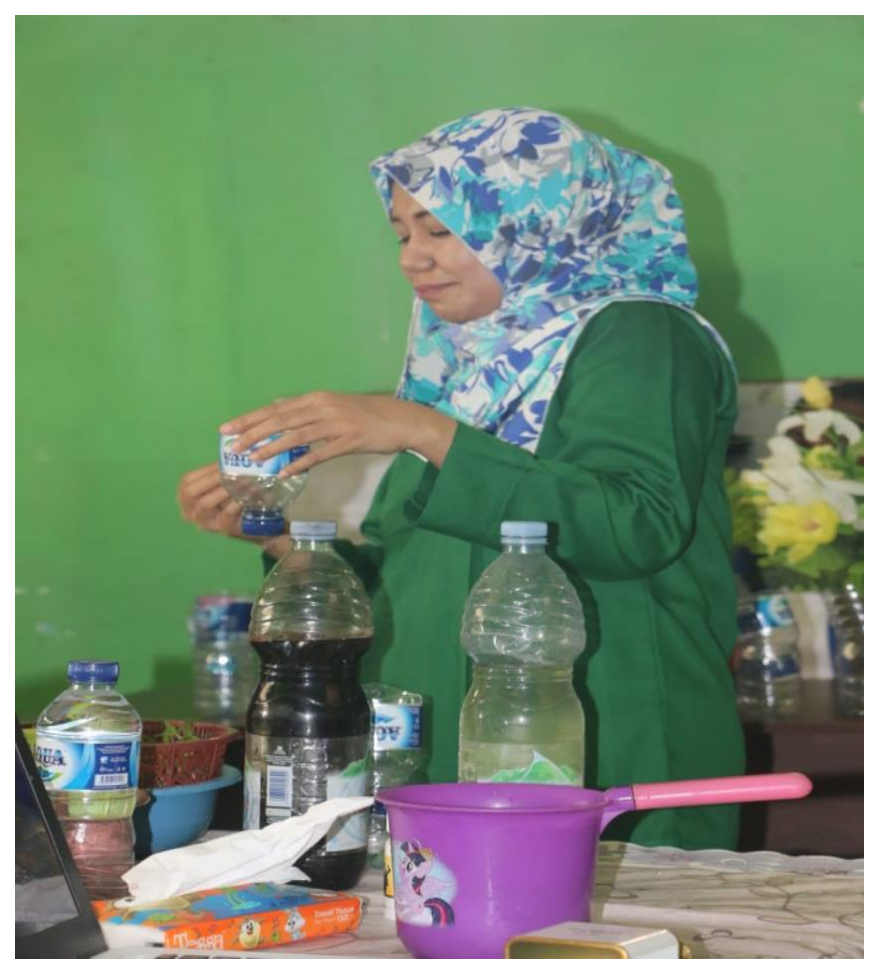

Gambar 3. Pemateri mempraktekkan tahapan pembuatan media tanam hidroponik.

2) Selanjutnya pada bagian botol plastik yang ada penutupnya (bagian leher botol) dan juga bagian penutup botol dilubangi dengan paku atau bisa degan solder. Lubangnyapun ukurannya kecil dan banyak..

3) Mengambil Botol plastik yang sudah dibelah 2 dan telah dilubangi.

4) Botol bagian bawah kemudian dibalut dengan lakban hitam diseluruh dindingnya, maksudnya adalah untuk mencegah bagian dalam berlumut apabila terkena cahaya matahari..

5) Pada bagian bawah botol diisi air kurang lebih 1 liter lalu ditambahkan pupuk yang sudah dilarutkan sebanyak $5 \mathrm{ml}$ (1 liter air : $5 \mathrm{ml}$ pupuk cair).

6) Masukkan sumbu pada bagian botol yang ada penutupnya.

7) Pada belahan botol atas yang telah dilubangi dimasukkan ke botol yang telah diisi air dan pupuk, dengan tutup botol mengarah kebawah (kerucut terbalik).

8) Yang terakhir, memasukkan bibit yang sudah semai beserta rockwoolnya kedalam botol plastik berlubang. Usahakan bibit masih dalam keadaan terendam sebagian dan mengenai ujung sumbu. 
9) Meletakkan botol di area yang terkena sinar matahari tetapi tidak terkena air hujan agar bibit tumbuh dengan baik.

Setelah rangkaian tahapan yang telah dicontohkan oleh pemateri selesai maka, kegiatan selanjutnya yakni Pemateri memberikan kesempatan untuk masing-masing peserta melakukan hal yang sama seperti yang telah dicontohkan oleh Pemateri kecuali dalam tahapan pelarutan pupuk. Peserta bisa mengambil pupuk yang telah dilarutkan oleh pemateri untuk mengisi botol yang mereka gunakan untuk menanam dengan hidroponik WICK.

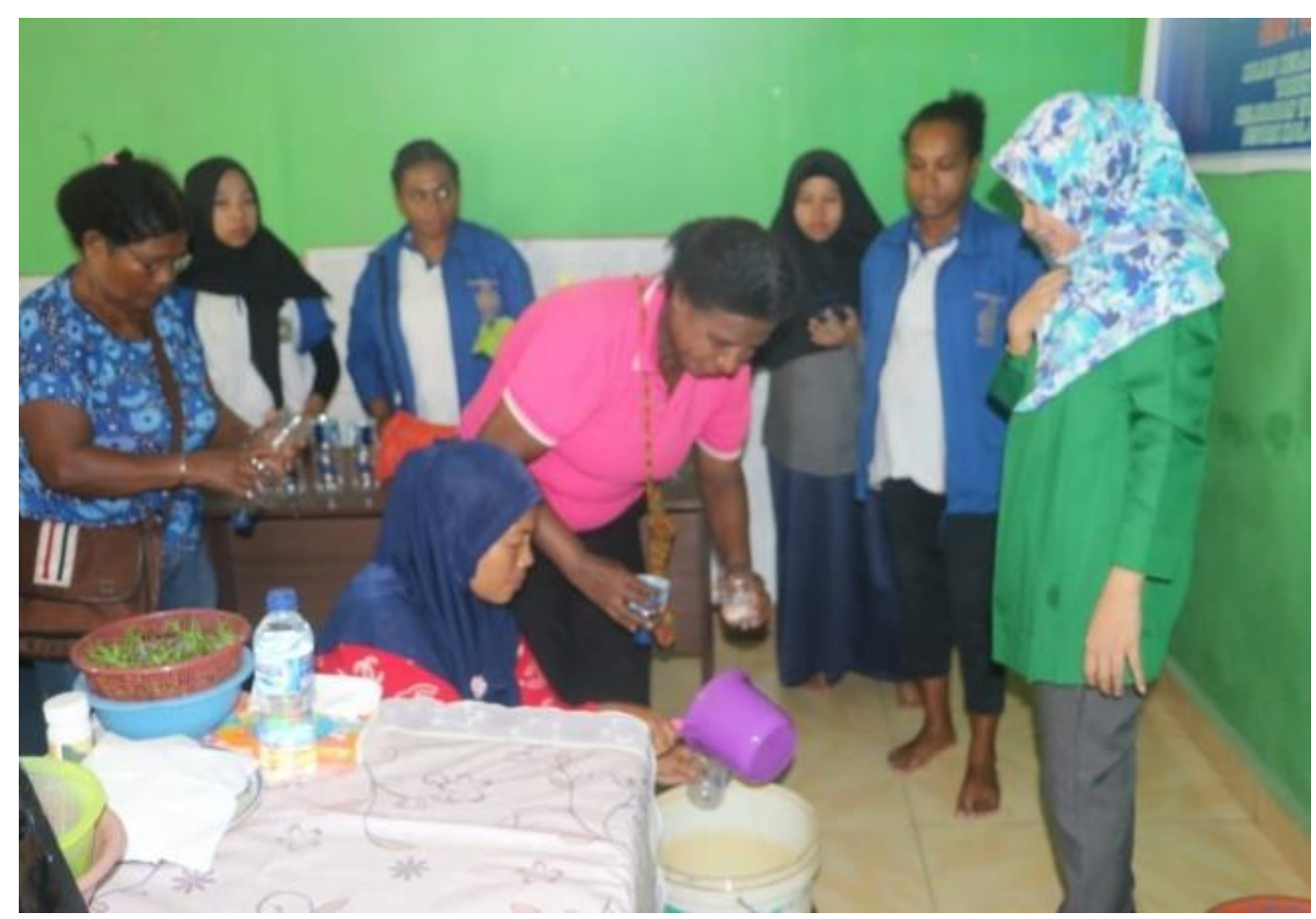

Gambar 4. Masing-masing peserta mulai mencontohkan setiap tahapan yang telah dipraktekkan dan pemateri mendampingi.

Dalam praktek yang dilakukan oleh peserta dalam hal ini warga masyarakat Kelurahan Tampa Garam, seringkali masih bertanya tahapan-tahapan yang dicontohkan sebelumnya, tetapi pada dasarnya antusias mereka sangat tinggi sehingga pemateri masih terus mendampingi bahkan selalu mengulang rangkaian proses hingga peserta benar-benar mahir dan bisa melakukannya sendiri di rumah.

\section{HASIL DAN PEMBAHASAN}

Dalam pelaksanaan pelatihan menanam kangkung dengan sistem hidroponik WICK, warga masyarakat yang datang dan menjadi peserta memperlihatkan antusiasme yang luar biasa. Dari diskusi yang dilakukan terbesit satu fakta bahwa sebenarnya warga selalu ingin bercocok tanam, 
tetapi karena keterbatasan lahan dan proses bercocok tanam secara konvensional tidak mudah, jadi pekarangan yang mereka mliki hanya dijadikan sebagai lahan parkir dan ada juga yang menanam bunga-bunga. Dengan adanya pelatihan ini peserta yang ada dapat bercocok tanam dengan mudah dan murah dengan sistem hidroponik yang telah dicontohkan. Hidroponik menurut Setiawati (2018), adalah proses menumbuhkan tanaman dengan tidak menggunakan tanah, caranya dengan menggantinya dengan air. Selain tidak meggunakan tanah juga dapat dilakukan di pekarangan rumah. Almasshabur (2018) menyatakan bahwa menggunakan sistem hidroponik artinya tidak perlu menggunakan lahan luas dan tanah seperti bercocok tanam pada umumnya, selain itu tidak memerlukan banyak biaya karena media hidroponik dapat dibuat dengan bendabenda bekas.

Secara garis besar keuntungan menanam dengan sistem hidropnik, yakni :

1. Tidak membutuhkan tanah

2. Air akan terus bersirkulasi di dalam sistem dan bisa digunakan untuk keperluan lain, misalnya dijadikan akuarium.

3. Pengendalian nutrisi lebih sederhana sehingga nutrisi dapat diberikan secara lebih efektif dan efisien.

4. Relatif tidak menghasilkan polusi nutrisi ke lingkungan.

5. Memberikan hasil yang lebih banyak.

6. Mudah dalam memanen hasil

7. Steril dan bersih

8. Media tanam dapat digunakan berulang kali

9. Bebas dari tumbuhan pengganggu/gulma

10. Tanaman tumbuh lebih cepat

Dalam pelatihan ini, karena menggunakan botol plastik bekas air mineral yang dapat ditemukan dengan mudah dan dijadikan sebagai media tanam ini sangat membantu program pemerintah kota sorong dalam penanganan limbah pastik dan juga tentunya mendukung keberlanjutan program ramah lingkungan..

Penerapan sistem hidroponik ada budidaya kangkung merupakan pilihan yang tepat pada kondisi saat ini. Hal tersebut dipengaruhi oleh kondisi social ekonomi masyarakat. Gaya hidup masyarakat saat ini cenderung pola hidupnya komsumtif. Selain itu kemudahan dalam pertanian hidroponik lebih mudah ketimbang dengan pertanian konvensional dengan hasil produksi yang sama. Hal ini sesuai dengan pendapat dari Syahra (2011) yang mengemukakan bahwa pertanian hidroponik WICK lebih murah karena hanya bermodalkan barang bekas, bahan-bahan simpel, serta ketekunan dan kecermatan, setiap orang bsa melakukan dan bisa menuai hasil tanaman yang 
banyak dan sehat. Iwok (2015) memberi tanggapan yang sama yakni dari sekian banyak sistem hidroponik yang ada, sistem hidroponik WICK yang paling mudah. Bukan hanya karena cara pembuatannya yang paling mudah, tapi dari sisi biaya juga yang paling murah.

\section{SIMPULAN}

Pelatihan menanam sayuran dengan sistem hidroponik WICK mendapatkan respon yang sangat luar biasa dari peserta pelatihan dan juga pejabat kelurahan dalam hal ini Lurah Tampa Garam, terbukti kehadiran warga yakni 68 orang, bahkan mereka meminta agar pemateri bisa melakukan pelatihannya secara berkesinambungan di Kelurahan Tampa Garam dimasing-masing RT yang ada dalam lingkup Kelurahan Tampa Garam. Pelatihan hidroponik WICK yang diberikan kepada warga dari segi biaya atau input yang digunakan sangatlah terjangkau dan ramah lingkungan karna penggunaan barang bekas.

Selain itu, cara bercocok tanam dengan hidroponik WICK tidak memerlukan lahan yang luas melainkan pekarangan sempit yang dimiliki warga tetap bisa melakukannya dan proses perawatan yang gampang dengan produksi yang banyak biasa membantu warga dalam menghemat pengeluaran atau belanja akan sayuran.

\section{DAFTAR PUSTAKA}

Almasshabur. 2018. 3 Cara Menanam Hidroponik dengan Sistem WICK. Ilmubudidaya.com. https://www.google.co.id/amp/s/ilmubudidaya.com/cara-menanam-hidroponik-dengansistem-wick/amp. Diakses pada tanggal 1 April 2019.

Iwok Abqary. 2015. Hidroponik Sederhana Sistem Sumbu (WICK). Tasikmalaya. https://iwok.blogspot.com/2015/05/hidroponik-sederhana-sistem-sumbuwick.html?m=1.Diakses pada tanggal 4 April 2019.

Setiawati Agnes. 2018. Inilah Keuntungan Hidroponik, Metode Cocok Tanam di Lahan Terbatas. https://www.google.co.id/amp/s/idea.grid.id/amp/099943043/inilah-keuntunganhidroponik-metode-cocok-tanam-di-lahan-terbatas. Diakses pada taggal 4 April 2019.

Syahra Syabani Tiara. 2011.Cara Praktis Membuat Hidroponik WICK System dari Botol Bekas, Cek Yuk!. Yogyakarta:newsletter99.co. https://www.99.co/blog /indonesia/cara-praktismembuat-hidroponik-wick-system-botol-bekas-cek-yuk/. Diakses pada tanggal 1 April 2019.

Wijaya Ranti dan Nurul Fajeriana M. 2018. Hasil dan Pertumbuhan Tanaman Selada (Lactuca sativa L.) dalam Sistem Akuaponik Ikan Nila, Ikan Lele, dan Ikan Pelangi. Jurnal Median Volume X Nomor 3 Bulan Oktober halaman 14-22. Universitas Muhamadiyah Sorong. Kota Sorong. Papua Barat. 